\title{
The Antioxidative Capacity of Kefir Produced from Goat Milk
}

\author{
Lutfiye Yilmaz-Ersan, Tulay Ozcan, Arzu Akpinar-Bayizit, and Saliha Sahin
}

\begin{abstract}
In this present study, the antioxidant properties of kefir produced from goat milk with kefir grains were investigated. The antioxidant capacity of kefir was evaluated by assessing the DPPH (2,2-Diphenyl-1-picrylhydrazyl), the ABTS-based method [2,2'-azino-bis-(3-ethylbenzthiazoline-6sulphonic acid)] radical-scavenging activity and ferric reducing antioxidant power (FRAP) at different stages of fermentation and storage period. Generally, the antioxidant capacity of goat milk-kefir samples was mainly dependent on the fermentation and storage period and good stability in DPPH, ABTS and FRAPS assays. During fermentation and storage, the total phenolic content in samples demonstrated significantly decreased.
\end{abstract}

Index Terms-Kefir, goat milk, antioxidant.

\section{INTRODUCTION}

In recent years, the consumption of goat milk and its products have been gaining more interest by consumers and producers due to their nutritional and bio-functional properties. Goat milk has higher contents of dry matter, total protein and casein, milk fat and mineral substances compared with cow milk. The fatty acid composition of goat milk is characterized by small sized fatty acid globules, high levels of medium-chain fatty acids and short-chain fatty acids such as caproic, caprylic and capric acid. This composition has distinct beneficial effects for human nutrition and health, like reducing cholesterol. Because of

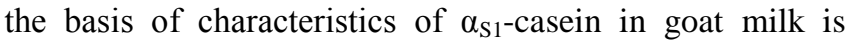
thought to have a lower allergenic potential than cow milk [1]-[3].

The word kefir is derived from the Turkish 'kef', which means 'pleasant taste'. Kefir is a fermented carbonated milk beverage originating from the Balkans, Eastern Europe and the Caucasus, and has been believed to be good for human health since early times. Traditionally, it is the product of lactic-alcoholic fermentation of kefir grains which contain a symbiotic mixture group of microflora, such as lactic acid and acetic acid bacteria, yeasts, and mycelial fungi embedded in a slimy polysaccharide matrix named kefiran [4].

Kefir grains are gelatinous irregularly masses, white or

Manuscript received February 5, 2015; revised April 15, 2015. This work was supported by a Commission of Scientific Research Projects of Uludag University, Bursa, Turkey (QUAP (Z) 2012/7).

Lutfiye Yilmaz-Ersan, Tulay Ozcan, and Arzu Akpinar-Bayizit are with the Department of Food Engineering, Faculty of Agriculture, Uludag University, Bursa, Turkey (e-mail: lutfiyey@uludag.edu.tr, tulayozcan@uludag.edu.tr, abayizit@uludag.edu.tr).

Saliha Sahin is with the Department of Chemistry, Faculty of Science and Arts, Uludag University, Bursa, Turkey (e-mail: salihabilgi@uludag.edu.tr.) lightly yellow in colour, and look like tiny clumps of cauliflower varying in size from 1 to $6 \mathrm{~mm}$ in diameter $(0.3-3.5 \mathrm{~cm})$. The function of the microorganisms of the kefir grains during fermentation may include the production of lactic acid, natural antibiotics, all of which are able to inhibit the growth of undesirable and pathogenic microorganisms in kefir milk. However, kefir has a uniform creamy consistency with acidic, yeasty flavor, a low alcohol content and contains vitamins (vitamin $\mathrm{B}_{1}, \mathrm{~B}_{12}, \mathrm{~K}$ and folic acid), minerals, amino acids, easily digestible complete proteins, and a variety of aromatic substances, such as acetaldehyde, acetoin, and diacetyl that give it its characteristic flavor [5], [6].

Kefir has long being considered beneficial to human health. For example, kefir is good for the enhancement of the immune system, digestive health, the clinical treatment of metabolic diseases, hypertension, ischemic heart disease (IHD), and allergies. However, it has antimicrobial, antitumor, antiviral, antimutagenic, antiinflammatory and antioxidant effects [7]-[13].

Recent studies have focused on the naturally occurring antioxidant components of milk and milk products, such as amino acids (including tyrosine and cysteine), vitamins (i.e. A and E), carotenoids, and enzymatic systems, mainly represented by superoxide dismutase, catalase and glutathione peroxidase [14]-[18]. It has been shown that fermented milk products, such as yoghurt, kefir and cheese possess antioxidant capacities and are able to scavenge radicals, such as superoxide radicals, hydroxyl radicals, and peroxide radicals, inhibit ascorbate and linoleic acid autoxidation, capture reactive oxygen species, as well as reduce the power or chelating activity [19]-[28].

Although goat milk is widely used for the manufacture of many different types of fermented milk products, little information is available with respect to the antioxidant properties on the kefir produced from goat milk with commonly used kefir grains. The main objective of the present study was to determine the antioxidant capacity of goat milk kefir at different stages of fermentation and storage.

\section{MATERIALS AND MEthodS}

\section{A. Kefir Grains and Inoculum Preparation}

The kefir grains were obtained from the Department of Food Engineering, University of Uludag, Bursa, Turkey. The inoculum was prepared by cultivating kefir grains in pasteurized skim milk containing $0.15 \%$ fat at $25^{\circ} \mathrm{C}$ for $24 \mathrm{~h}$, renewed daily, for a duration of 7 days. After this time, the grains were filtered to remove the clotted milk and rinsed 
with sterile distilled water. Upon receipt, kefir grains were inoculated into pasteurized milk and incubated at $25^{\circ} \mathrm{C}$ until used.

\section{B. Kefir Production}

Raw goat milk was obtained from the Uludag University Dairy Farm and heated to $90^{\circ} \mathrm{C}$ for $10 \mathrm{~min}$ in a water bath, before cooling to the inoculation temperature. The heattreated milk was inoculated with $5 \%(\mathrm{v} / \mathrm{w})$ of the activated kefir grains and incubated at $25^{\circ} \mathrm{C}$ for $20 \mathrm{~h}$ until the desired final $\mathrm{pH}$ of the product (4.5-4.6) was reached. Samples were collected at intervals of $4 \mathrm{~h}$ during fermentation. At the end of the fermentation process, the kefir was filtered through three layers of cheese cloth in order to remove the kefir grains. The kefir drink was filled into $200 \mathrm{~mL}$ bottles and cooled down to $4-6^{\circ} \mathrm{C}$ and stored at $4 \pm 1{ }^{\circ} \mathrm{C}$ until the analysis. The samples were analyzed on the $1^{\text {st }}, 7^{\text {th }}, 14^{\text {th }}$ and $21^{\text {st }}$ days of storage.

\section{Preparation of the Kefir Extracts}

The kefir samples ( $2 \mathrm{~g})$ were blended with $20 \mathrm{~mL}$ of extraction solution (methanol/water, 70:30, v/v) and stirred at $20 \pm 1^{\circ} \mathrm{C}$ for $4 \mathrm{~h}$ in the dark with the help of a magnetic stirrer. The suspension was centrifuged at 3,500 rpm for 10 minutes and filtered through sheets of qualitative filter paper ( $75 \mathrm{~g} \mathrm{~m}^{2}, 0.2 \mathrm{~mm}$ thickness). These supernatants were used to determine antioxidant capacity by ABTS, DPPH and FRAP and the total phenolic contents.

\section{Antioxidant Capacity Assay}

\section{2,2-Diphenyl-1-picrylhydrazyl scavenging activity \\ (DPPH) radical}

The scavenging effect of kefir was determined with the DPPH method according to Sahin et. al. [29]. The results were expressed as $\mathrm{mg}$ trolox equivalent (TE) per $100 \mathrm{~mL}$ of the sample.

\section{2,2'-azino-bis-(3-ethylbenzthiazoline-6-sulphonic acid) (ABTS) radical scavenging activity}

Estimation of $\mathrm{ABTS}^{+}$radical scavenging activity of sample was determined with ABTS method, as described in the literature [29]. The results were expressed as $\mathrm{mg}$ trolox equivalent (TE) per $100 \mathrm{~mL}$ of sample.

\section{E. Ferric Reducing Antioxidant Power Assay}

The ferric reducing ability of samples (FRAP) as a measure of antioxidant power was performed by the method described by Benzie and Strain [30]. The results were expressed as mg trolox equivalent (TE) per $100 \mathrm{~mL}$ of the sample.

\section{F. Total Phenolic Assay}

Total phenolic content, using Folin-Ciocalteu reagent, was carried out according to the procedure reported in the literature [31]. The total phenol content was calculated from a standard curve of gallic acid and results were expressed as $\mathrm{mg}$ of gallic acid equivalents (GAE) per $100 \mathrm{~mL}$ of sample.

\section{G. Statistical Analysis}

All statistical analyses were performed using the Statistical software package. The results were submitted to variance analysis (ANOVA), at $1 \%$ and $5 \%$ significance levels and presented as means \pm standard error of the mean.
Analysis of variance with mean separations using the LSD multiple range test as the level of significant difference was used to determine the effect of fermentation and storage time on the antioxidant capacity. Different letters were used to label values with statistically significant differences among them.

\section{RESULTS AND DISCUSSION}

The total antioxidant capacity of samples was evaluated using three different methods to scavenge DPPH and ABTS free radicals, as well as reducing prooxidant metal ions (FRAP) and presented in Table I and II as a function of fermentation and storage time respectively.

\section{2,2-Diphenyl-1-picrylhydrazyl (DPPH) radical scavenging activity}

DPPH, a stable organic free radical, is a recognized proton-radical scavenging activity indicating the capacity of the antioxidants to donate hydrogen or electrons. The assay is widely used due to its simplicity, rapidity, sensitivity and reproducibility. Based on this principle, the reduction in the concentration of the DPPH solution in the presence of a hydrogen-donating antioxidant is allowed to monitor the decrease in its absorbance at a characteristic wavelength and lead to the formation of a non-radical form DPPH-H [32].

In this study, we found that immediately following the addition of kefir grains to the goat milk, the DPPH radicalscavenging activity appeared to have increased. After the incubation of $8 \mathrm{~h}$, the percentage of scavenging ability of goat milk - kefir was significantly greater than those of milk. Several authors also reported that the DPPH radicalscavenging activity of dairy products produced by fermentation with microorganisms increased [33]-[35]. Such a result implies that goat milk-kefir is a good scavenger for DPPH radical; thus, kefir can afford protection against proton free radicals. Significant differences in the DPPH scavenging activity were found among the four storage days $(p<0.01)$. The DPPH scavenging activity of kefir samples increased with storage days (Table II). The highest DPPH inhibition after 21 days of cold storage may be attributed to the metabolism of microorganisms in kefir grains even at low temperatures $(p<0.01)$.

\section{2,2'-azino-bis-(3-ethylbenzthiazoline-6-sulphonic acid) (ABTS) radical scavenging activity}

The ability of the sample to quench a radical was measured using the ABTS method. Many compounds such as trolox, urate, ascorbate, cysteine, glutathione and bilirubin can be exerted in this method. Generally, TEAC values and the scavenging capacity of trolox (vitamin $\mathrm{E}$ analogue, water soluble) can be measured using the ABTS scavenging capacity. In the analysis of the kinetic of free radical scavenging ABTS, the highest free radical scavenging in this study appeared to be greatest following the addition of kefir grains to the goat milk (Table I). It can be seen that the ABTS activity in kefir appeared to change during kefir fermentation $(p<0.01)$. During storage, the ABTS activities of goat milk-kefir showed statistically significant variation $(p<0.01)$, as well as a detected drop in the ABTS values between the $14^{\text {th }}$ and $21^{\text {st }}$ day of cold 
storage. In this study, results agree with the antioxidant capacity detected in bovine milk and whey (ABTS method) by Chen et al. [20], who identified casein as a major $\mathrm{ABTS}^{+}$scavenger in milk.

TABLE I: EFFECT OF FERMENTATION TIME UPON THE ANTIOXIDANT CAPACITY OF GOAT-MILK KEFIR

\begin{tabular}{|c|c|c|c|c|c|c|}
\hline & \multicolumn{7}{|c|}{ Fermentation Time (hours) } \\
\cline { 2 - 7 } & $\mathbf{0}$ & $\mathbf{4}$ & $\mathbf{8}$ & $\mathbf{1 2}$ & $\mathbf{1 6}$ & $\mathbf{2 0}$ \\
\hline DPPH & $0.63 \pm 0.042^{\mathrm{e}}$ & $3.11 \pm 0.000^{\mathrm{c}}$ & $7.20 \pm 0.283^{\mathrm{a}}$ & $4.72 \pm 0.170^{\mathrm{b}}$ & $1.93 \pm 0.042^{\mathrm{d}}$ & $3.24 \pm 0.057^{\mathrm{c}}$ \\
\hline ABTS & $17.41 \pm 0.014^{\mathrm{a}}$ & $12.25 \pm 0.071^{\mathrm{e}}$ & $13.03 \pm 0.042^{\mathrm{d}}$ & $16.50 \pm 0.141^{\mathrm{b}}$ & $14.58 \pm 0.113^{\mathrm{c}}$ & $10.96 \pm 0.000^{\mathrm{f}}$ \\
\hline FRAP & $4.54 \pm 0.057^{\mathrm{d}}$ & $4.44 \pm 0.099^{\mathrm{d}}$ & $8.04 \pm 0.057^{\mathrm{a}}$ & $7.01 \pm 0.014^{\mathrm{b}}$ & $5.74 \pm 0.141^{\mathrm{c}}$ & $4.29 \pm 0.127^{\mathrm{d}}$ \\
\hline (TPC as GAE) $\mathbf{~ m g / g}$ & $170.54 \pm 0.198^{\mathrm{a}}$ & $104.73 \pm 0.184^{\mathrm{b}}$ & $90.36 \pm 0.226 \mathrm{c}$ & $83.88 \pm 0.170^{\mathrm{d}}$ & $83.70 \pm 0.283^{\mathrm{e}}$ & $65.48 \pm 0.113^{\mathrm{f}}$ \\
\hline
\end{tabular}

${ }^{a-f}$ Means in the same line followed by different lowercase letters represent significant differences $(p<0.01)$; ABTS=2, 2-Azinobis $(3$ ethyl benzothiazoline)-6-sulphonic acid radical scavenging activity; DPPH= 2, 2-Diphenyl-1-picrylhydrazyl radical scavenging activity (\% Inhibition); FRAP= Ferric reducing antioxidant power; TPC= total phenolic content; GAE=gallic acid equivalent

TABLE II: EFFeCT OF Storage Time UPON THE ANTIOXIDANT CAPACITY OF GOAT-MiLK KeFIR

\begin{tabular}{|c|c|c|c|c|}
\hline \multirow{2}{*}{} & \multicolumn{4}{|c|}{ Storage Time (Days) } \\
\cline { 2 - 5 } & $\mathbf{1}$ & $\mathbf{7}$ & $\mathbf{1 4}$ & $\mathbf{2 1}$ \\
\hline DPPH & $4.48 \pm 0.679^{\mathrm{ab}}$ & $3.98 \pm 0.219^{\mathrm{b}}$ & $5.04 \pm 0.057^{\mathrm{a}}$ & $5.44 \pm 0.198^{\mathrm{a}}$ \\
\hline ABTS & $11.93 \pm 0.022^{\mathrm{ab}}$ & $11.29 \pm 0.127^{\mathrm{b}}$ & $12.19 \pm 0.269^{\mathrm{a}}$ & $11.14 \pm 0.198^{\mathrm{b}}$ \\
\hline FRAP & $4.35 \pm 0.495^{\mathrm{b}}$ & $3.99 \pm 0.000^{\mathrm{b}}$ & $6.33 \pm 0.467^{\mathrm{a}}$ & $7.13 \pm 0.184^{\mathrm{a}}$ \\
\hline (TPC as GAE) $\mathbf{m g} / \mathbf{g}$ & $59.66 \pm 0.085^{\mathrm{a}}$ & $63.89 \pm 0.156^{\mathrm{c}}$ & $69.96 \pm 0.057^{\mathrm{a}}$ & $66.81 \pm 0.156^{\mathrm{b}}$ \\
\hline
\end{tabular}

${ }^{a-f}$ Means in the same line followed by different lowercase letters represent significant differences $(p<0.01)$; ABTS $=2,2$-Azinobis ( 3 ethyl benzothiazoline)-6-sulphonic acid radical scavenging activity; $\mathrm{DPPH}=$ 2, 2-Diphenyl-1-picrylhydrazyl radical scavenging activity (\% Inhibition); FRAP $=$ Ferric reducing antioxidant power; $\mathrm{TPC}=$ total phenolic content; GAE=gallic acid equivalent

\section{A. Ferric Reducing Antioxidant Power}

FRAP assay, a simple, convenient and reproducible method, is based on the reduction of a ferrictripyridyltriazine (TPTZ) complex to its ferrous form [30]. Regarding the percentages of inhibition of ferrozine$\mathrm{Fe}^{+2}$ complex formation with goat milk-kefir, literature reports are scarce. The ferrous ion chelating activities of goat milk-kefir was estimated and depicted in Table I. As observed in the present study, we found that goat milk-kefir has a significant increase in its ferrous ion chelating activity during the first $8 \mathrm{~h}$-fermentation time $(p<0.01)$.

The $\mathrm{Fe}^{+2}$-chelating capacity of the kefir samples during storage time is also presented in Table II. The chelating capability tended to increase with increased storage time. The maximum value was reached after 21 days of storage, with approximately a 2-fold increase when compared to the first day of storage.

\section{B. Total Phenolic Content}

Phenolic compounds, good sources of natural antioxidants in human diets, are found in noticeable amounts in milk derived from the feed. In this study, we found that goat milk-kefir fermented by kefir grains demonstrated significantly a decrease in phenolic content during fermentation $(p<0.01)$ and reached lower values after 20 hours of fermentation at $25^{\circ} \mathrm{C}$ (Table I). The decrease in phenolic content could also result from microbial degradation of phenolic structures as possible yeast and bacterial antimicrobial detoxification strategies [23]. The concentrations of total phenolic in samples during storage are shown in Table II. The total phenolic content of kefir samples ranged from 59.66 to $69.96 \mathrm{mg}$ GAE per $\mathrm{g}$ of sample. Duration of storage significantly $(p<0.01)$ affected the TPC in kefir samples, with the $14^{\text {th }}$ day of storage showing the highest concentration of TPC compared to the others days.

As various methods were used to test the antioxidant capacity, the results were expressed in a variety of ways which makes comparison difficult. In the present study, three different antioxidant capacity methods were used to screen radical scavenging activity as well as reducing prooxidant metal ions (FRAP). The measured antioxidant properties differed according to the fermentation and storage time. Generally, in this study the data obtained clearly shows fermentation time exhibited higher antioxidant activity compared with storage time. We found in this study that goat milk-kefir had radical scavenging activity, and in most cases the activities increased during the fermentation period. This might suggest that the antioxidative capacity was derived at least partly from milk peptides released by kefir grains. Several studies reported that the radical scavenging activity in fermented milk products may be influenced by milk protein proteolysis and organic acids as a result of starter culture activity during fermentation and during storage [35]-[37].

\section{CONCLUSION}

Kefir is greatly useful as a functional food because of its high nutritive and bio-functional values. However, goat milk and its specialty products also have nutritional, health and therapeutic benefits, due to these valuable dairy 
products being produced in the food industry. This study focused on screening the antioxidant capacity of kefir from goat's milk during the fermentation and storage process. Generally, the antioxidant capacity of goat milk-kefir fermented with kefir grains was mainly influenced by both the fermentation and storage period and good stability in DPPH, ABTS and FRAPS assays. The observation of increased antioxidant activities may offer a new range of goat milk-kefir with desirable multifunctional healthpromoting effects to consumers.

\section{ACKNOWLEDGMENT}

The authors are very grateful to the Commission of Scientific Research Projects of Uludag University, Bursa, Turkey (QUAP (Z) 2012/7) for the financial support of this study.

\section{REFERENCES}

[1] R. Attaie and R. L. Richter, "Size distribution of fat globules in goat milk," Journal of Dairy Science, vol. 835, pp. 940-944, 2000.

[2] S. Boycheva, T. Dimitrov, N. Naydenova, and G. Mihaylova, "Quality characteristics of yogurt from goat's milk, supplemented with fruit juice," Czech J. Food Sci., vol. 29, pp. 24-30, 2011.

[3] F. Yangılar, "As a potentially functional food: Goats' milk and products," Journal of Food and Nutrition Research, vol. 1, pp. 68-81, 2013.

[4] L. Yilmaz, T. Ozcan-Yilsay, and A. Akpinar-Bayizit, "The sensory characteristics of berry-flavoured kefir," Czech J. Food Sci., vol. 24, pp. 26-32, 2006.

[5] Z. B. Güzel-Seydim, A. C. Seydim, A. K. Greene, and A. B. Bodine, "Determination of organic acids and volatile flavor substances in kefir during fermentation," Journal of Food Composition and Analysis, vol. 13, pp. 35-43, 2000.

[6] E. R. Farnworth, "Kefir-A complex probiotic," in Food Science and Technology Bulletin, G. R. Gibson, Ed. IFIS Publishing, pp. 1-18, 2006.

[7] A. de Moreno de LeBlanc, C. Matar, E. Farnworth, and G. Perdigón, "Study of immune cells involved in the antitumor effect of kefir in a murine breast cancer model," Journal of Dairy Science, vol. 90, pp. 1920-1928, 2007.

[8] E. J. Kakisu, A. G. Abraham, P. F. Perez, and G. L. de Antoni, "Inhibition of Bacillus cereus in milk fermented with kefir grains," $J$. Food Protec., vol. 70, pp. 2613-2616, 2007.

[9] S. Cenesiz, A. K. Devrim, U. Kamber, and M. Sozmen, "The effect of kefir on glutathione (GSH), malondialdehyde (MDA) and nitric oxide (NO) levels in mice with colonic abnormal crypt formation (ACF) induced by azoxymethane (AOM)," Deut. Tierarztl. Woch., vol. 115, pp. 15-19, 2008.

[10] W. S. Hong, H. C. Chen, Y. P. Chen, and M. J. Chen, "Effects of kefir supernatant and lactic acid bacteria isolated from kefir grain on cytokine production by macrophage," Int. Dairy J., vol. 19, pp. 244251, 2009.

[11] Z. B. Guzel-Seydim, T. Kok-Tas, A. K. Greene, and A. C. Seydim, "Review: Functional properties of kefir," Critical Reviews in Food Science and Nutrition, vol. 51, pp. 261-268, 2011.

[12] F. P. Rattray and M. J. O'Connell, "Fermented Milks Kefir," in Encyclopedia of Dairy Sciences, $2^{\text {nd }}$ edition, J. W. Fukay, Ed. Academic Press, San Diego, USA, pp. 518-524, 2011.

[13] H. F. Huseini, G. Rahimzadeh, M. R. Fazeli, M. Mehrazma, and M. Salehi, "Evaluation of wound healing activities of kefir products," Burns, vol. 38, pp. 719-723, 2012.

[14] H. Lindmark-Månsson and B. Åkesson, "Antioxidative factors in milk," British Journal of Nutrition, vol. 84, pp. 103-110, 2000.

[15] J. B. German, C. J. Dillard, and R. E. Ward, "Bioactive components in milk," Current Opinion in Clinical Nutrition and Metabolic Care, vol. 5, pp. 653-658, 2002.

[16] S. Calligaris, L. Manzocco, M. Anese, and M. C. Nicoli, "Effect of heat-treatment on the antioxidant and pro-oxidant activity of milk," International Dairy Journal, vol. 14, pp. 421-427, 2004.

[17] A. Pihlanto, "Antioxidative peptides derived from milk proteins," International Dairy Journal, vol. 16, pp. 1306-1314, 2006.

[18] B. Usta and L. Yilmaz-Ersan, "Antioxidant enzymes of milk and their biological effects," Journal of Agricultural Faculty of Uludag University (Turkish), vol. 27, pp. 123-130, 2013.
[19] L. M. Tong, S. Sasaki, D. J. McClements, and E. A. Decker, "Mechanisms of the antioxidant activity of a high molecular weight fraction of whey," Journal of Agricultural and Food Chemistry, vol. 48, pp. 1473-1478, 2000.

[20] J. Chen, H. Lindmark-Mansson, L. Gorton, and B. Akesson, "Antioxidant capacity of bovine milk as assayed by spectrophotometric and amperometric methods," International Dairy Journal, vol. 13, pp. 927-935, 2003.

[21] E. Songisepp, T. Kullisaar, P. Hutt, P. Elias, T. Brilene, M. Zilmer, and M. Mikelsaar, "A new probiotic cheese with antioxidative and antimicrobial activity," J. Dairy Sci., vol. 87, pp. 2017-2023, 2004.

[22] J. R. Liu, M. J. Chen, and C. W. Lin, "Antimutagenic and antioxidant properties of milk-kefir and soymilk-kefir," J. Agric. Food Chem., vol. 53, pp. 2467-2474, 2005.

[23] P. P. McCue and K. Shetty, "Phenolic antioxidant mobilization during yogurt production from soymilk using kefir cultures," Process Biochemistry, vol. 40, pp. 1791-1797, 2005.

[24] T. Virtanen, A. Pihlanto, S. Akkanen, and H. Korhonen, "Development of antioxidant activity in milk whey during fermentation with lactic acid bacteria," Journal of Applied Microbiology, vol. 102, pp. 106-115, 2007.

[25] A. Lucas, D. Andueza, E. Rock, and B. Martin, "Prediction of dry matter, fat, ph, vitamins, minerals, carotenoids, total antioxidant capacity, and color in fresh and freeze-dried cheeses by visible-nearinfrared reflectance spectroscopy," J. Agric. Food Chem., vol. 56, pp. 6801-6808, 2008.

[26] A. Gupta, B. Mann, R. Kumar, and R. B. Sangwan, "Antioxidant activity of cheddar cheeses at different stages of ripening," International Journal of Dairy Technology, vol. 62, pp. 339-347, 2009.

[27] K. H. S. Farvin, C. P. Baron, N. S. Nielsen, and C. Jacobsen, "Antioxidant activity of yoghurt peptides: Part 1-in vitro assays and evaluation in x-3 enriched milk," Food Chemistry, vol. 123, pp. 1081-1089, 2010.

[28] M. C. Hilario, C. D. Puga, A. N. Ocana, and F. P. G. Romo, "Antioxidant activity, bioactive polyphenols in Mexican goats' milk cheeses on summer grazing," Journal of Dairy Research, vol. 77, pp. 20-26, 2010.

[29] S. Sahin, E. Isik, O. Aybastier, and C. Demir, "Orthogonal signal correction-based prediction of total antioxidant activity using partial least squares regression from chromatograms," Journal of Chemometrics, vol. 26, pp. 390-399, 2012.

[30] I. F. Benzie and J. J. Strain, "The ferric reducing ability of plasma (FRAP) as a measure of "antioxidant power": the FRAP assay," Anal. Biochem., vol. 239, pp. 70-76, 1996.

[31] S. Sahin, O. Aybastier, and E. Isik, "Optimisation of ultrasonicassisted extraction of antioxidant compounds from Artemisia absinthium using response surface methodology," Food Chem., vol. 141, pp. 1361-1368, 2013.

[32] T. Kulisic, A. Radonic, V. Katanilic, and M. Milos, "Use of different methods for testing antioxidative activity of oregano essential oil," Food Chem., vol. 85, pp. 633-640, 2004.

[33] M. Y. Lin and F. J. Chang, "Antioxidative effect of intestinal bacteria Bifidobacterium longum ATCC 15708 and Lactobacillus acidophilus ACTT 4356," Digest. Dis. Sci., vol. 45, pp. 617-1622, 2000.

[34] T. Nishino, H. Shibahara-Sone, H. Kikuchi-Hayakawa, and F. Ishikawa, "Transit of radical scavenging activity of milk products prepared by Maillard reaction and Lactobacillus casei strain Shirota fermentation through the hamster instestine," J. Dairy Sci., vol. 83, pp. 915-922, 2000.

[35] K. Suetsuna, H. Ukeda, and H. Ochi, "Isolation and characterization of free radical scavenging activities peptides derived from casein," The Journal of Nutritional Biochemistry, vol. 11, pp. 128-131, 2000.

[36] A. Lourens-Hattingh and B. C. Viljoen, "Yogurt as probiotic carrier food," Int. Dairy J., vol. 11, pp. 1-17, 2001.

[37] I. Correia, A. Nunes, I. F. Duarte, A. Barros, and I. Elgadillo, "Sorghum fermentation followed by spectroscopic techniques," Food Chem., pp. 853-859, 2004.

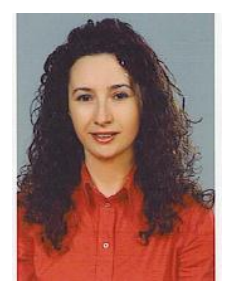

Lutfiye Yilmaz-Ersan is an associate professor of Department of Food Engineering at the Uludag University, Bursa, Turkey. More recently, she has worked dairy and dairy products. From 2007 to 2008 (14 months) she worked at University of NebraskaLincoln USA, Department of Food Science and Technology as a visiting scientist. Her research interests include dairy and dairy products, probiotics and prebiotics. 


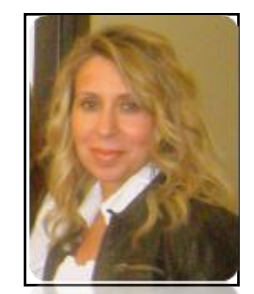

Tulay Ozcan is an associate professor of the Department of Food Engineering at the Uludag University, Bursa, Turkey. More recently, she has worked in the area of rheology and texture of dairy products. From 2005 to 2006 and 2010 (21 months) she worked at University of Wisconsin-Madison USA, Department of Food Science as a visiting scientist. Her research interests include dairy chemistry and biochemistry, rheological properties and microstructure of yogurt, texture of yogurt and cheese, the use of dairy and plant based proteins for the production of functional dairy products, probiotics and prebiotics, traditional cheeses and enzyme accelerated ripening of cheese, the use of fat replacer in dairy products and principles of nutrition.

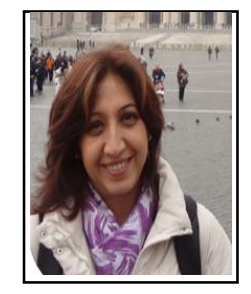

Arzu Akpinar-Bayizit is an assistant professor at the Department of Food Engineering, Uludag University, Bursa/Turkey. After having M.Sc. degree at Uludag University in 1994, she had her Ph.D. degree at the Department of Biological Sciences of the University of Hull, United Kingdom, in 1997. The topic of her Ph.D project funded by Higher
Education Council of Turkey was on fungal lipid metabolism, subsequently a novel hydroxylated fatty acid was identified from the sewage fungus, Leptomitus lacteus. The main lectures given by Mrs. Akpinar-Bayizit are instrumental analysis, microbial process technology, food fermentations and functional foods. Her research interests include fermentation technology, particularly microbial fermentations, and lipid technology. To date she has supervised 6 M.Sc. studies, and supervising ongoing 5 M.Sc. and 3 Ph.D. projects. She has published several research and review articles in international journals and has two book chapters.

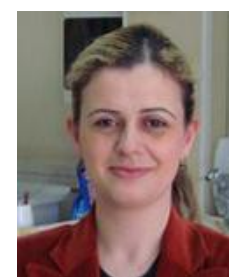

Saliha Sahin is an associate professor at the Department of Chemistry, Faculty of Science and Arts, Uludag University, Bursa, Turkey. Her research interests include HPLC, LC-MS, GC-MS, chemometrics analytical chemistry, phenolic and antioxidative compounds in natural products. 